\title{
Clear cell atypical fibroxanthoma: A case report and review of the literature
}

\author{
PATROKLOS KATAFYGIOTIS
}

First Department of Pathology National and Kapodistrian University of Athens, 11527 Athens, Greece

Received February 23, 2021; Accepted May 18, 2021

DOI: 10.3892/wasj.2021.109

\begin{abstract}
Clear cell atypical fibroxanthoma (CCAFX) is a rare tumor of uncertain differentiation first described in 1987, of which 20 cases have thus far been studied in detail and reported in the English literature. CCAFX is regarded as a skin tumor and without a wide-range immunohistochemical application, it is relatively impossible to differentiate it from other well-known malignancies with a clear cell phenotype. In the majority of cases, CCAFX has a rather indolent course; however, it can produce local recurrences, particularly if an incomplete excision has been made and in more rare cases, it can lead to regional lymph node metastases. The present study describes the case of a male patient with a rapidly growing CCAFX highlighting the vast clinicopathological differential diagnosis of this tumor and describing its course one year following its surgical excision. The tumor was examined immunohistochemically and was found to express several fibrohistiocytic antigens (such as CD68, $\alpha 1$-antichymotrypsin and FactorXIIIa, as well as CD10, D2-40 and CD99); however, it did not express melanocytic, hormonal receptors or cytokeratins. In addition, the current study reviews and discusses the most prominent clinicopathologic features of this rare cutaneous tumor of uncertain differentiation.
\end{abstract}

\section{Introduction}

Clear cell atypical fibroxanthoma (CCAFX) is a rare variant of atypical fibroxanthoma (AFX) which was initially described in 1961 by Helwig (1), whereas the first description of the clear cell variant was provided by Patterson et al (2) in 1987, with only 20 cases reported in the English literature to date, at least to the best of the author's knowledge. The majority of cases have been adequately studied and explicit details have been reported (1-14). The line of differentiation/histogenesis of CCAFX is uncertain. Considering the fact that this is a variant

Correspondence to: Dr Patroklos Katafygiotis, First Department of Pathology National and Kapodistrian University of Athens, Mikras Asias 75, 11527 Athens, Greece

E-mail: patlamkat@yahoo.gr

Key words: clear cell atypical fibroxanthoma, immunohistochemistry of atypical fibroxanthoma (AFX) originating from a primitive mesenchymal cell or a transitional form of a cell, myofibroblastic and fibrohistiocytic differentiation seems probable (3). CCAFX was included for the first time in the latest edition of the World Health Organization (WHO) classification of tumors of uncertain differentiation (15). CCAFX usually presents an indolent course, although it can occasionally be aggressive, producing local recurrences and more rarely, regional and distant metastases (16). In the present study, the clinicopathological and immunohistochemical features of a new case of CCAFX are described. In addition, the present study provides a review on this rare variant of AFX.

\section{Case report}

A 78-year-old bald Caucasian male, who was a former bus driver in the public sector, with Fitzpatrick phototype III, presented at General Hospital of Arta Greece with a lesion on the scalp that suddenly became raised, growing rapidly within two weeks and became ulcerated. The patient reported a history of sun exposure, was diabetic without immunosuppression, and suffered from coronary artery disease, chronic renal failure, gout and hypertension. He has been diagnosed twice for basal cell carcinoma in the external ear 25 years ago and recently, on the nose. The patient provided his informed consent prior to the preparation of the present study.

Clinical findings. The lesion was examined initially by a general practitioner and the patient was referred to a skin specialist. The dermatologist suggested the excision of the lesion as soon as possible as the clinical impression was squamous cell carcinoma or basal cell carcinoma, highlighting the rapidly growing lesion. A physical examination revealed an oval-shaped, well-demarcated, firm, slightly tender, pink-red nodule of $1.3 \mathrm{~cm}$ in diameter, with an ulcerated surface on the scalp (Fig. 1).

Therapeutic intervention. The lesion was surgically excised under local anesthesia two weeks after its first notification by the patient and was examined histologically.

Diagnostic assessment. All materials and methods applied in the present study were performed at the First Department of Pathology, National and Kapodistrian University of Athens according to the protocol for the histologic diagnosis. 
A microscopic examination revealed a tumor infiltrating the whole dermis, whereas the overlying epidermis was completely ulcerated (Fig. 2). The tumor consisted of large, pleomorphic, spindle-shaped and epithelioid cells, with centrally placed nuclei, with some of these being multinucleated with an eosinophilic or foamy/clear cytoplasm, which did not stain for periodic acid-Schiff (PAS) or PAS-diastase infiltrating into a hyalinized stroma (Fig. 3). The cells were arranged without a defined pattern, lacking peripheral palisading, as shown by H\&E staining (Fig. 2). In the papillary dermis on the tumor border, an epidermal collarette was observed and the tumor was shown to come into contact with the basal epidermal layer (Fig. 2). Elastic Verhoeff-van Gieson staining revealed a degenerative process of elastic fiber in the superficial dermis. In the reticular dermis, the tumor had a 'pushing' and well demarcated margin (Fig. 2). Numerous mitoses were observed, some of these being atypical. The inflammatory infiltrate consisted mainly of lymphocytes, mast cells and a few histiocytes. As compared with the rest of the dermis, mast cells, which were dispersed in the lesion, were more concentrated in the neoplasm. Immunohistochemically, the tumor cells diffusely expressed CD10 (Fig. 4A), CD68 (Fig. 4B), CD99 (Fig. 5A), D2-40 (Fig. 5B), $\alpha 1$-antichymotrypsin and variably FactorXIIIa (Fig. 5C) and p63 (nuclear staining in a small number of cells in the deepest point of tumor infiltration). The proliferation index (Ki-67) was 93\% (Fig. 6A). The cells exhibited strong nuclear staining for p53 (94\%) (Fig. 6B). Tumor cells were not immunoreactive for the following: Cytokeratin AE1/AE3 (CKAE1/AE3), cytokeratin 34bE12 (CK903), HMB45, MART-1, CD34, Desmin, SMA, c-kit (CD117), ERG, calponin and S100 (data not shown). No molecular analysis has yet been conducted for the case described in the present study.

Follow-up and outcomes. The case reported herein is described after one year of the tumor onset on the scalp. The patient has been followed-up every six months by an oncologist and he is free of metastasis or recurrence. A laboratory investigation with a CT scan of the head/neck and thorax, as well as the palpation of cervical lymph nodes of the head/neck region following the diagnosis, was normal. During this time, visits to the dermatologist led to the diagnosis of another lesion on the nose, which was diagnosed as basal cell carcinoma.

\section{Discussion}

CCAFX is a malignant tumor, most often diagnosed on the scalp, and occasionally in other sun-exposed skin areas of the periauricular region, anti-helix, temple, nose, cheek, shoulder, forearm, hand and leg (1-14). Is a very rare variant of AFX with a vast histopathological differential diagnosis. In 2016, a study based on 112 patients with AFX diagnosed (between 2004 and 2014) was published in Spain, presenting only six cases of CCAFX (4). The clinical and pathological findings from the literature are summarized in Table I. Following its first description in 1987 (2), 20 cases have been described in the literature to date (1-14). Some cases of CCAFX have probably been reported under a different diagnosis, since the use of immunohistochemical staining has facilitated the confirmation of this entity and

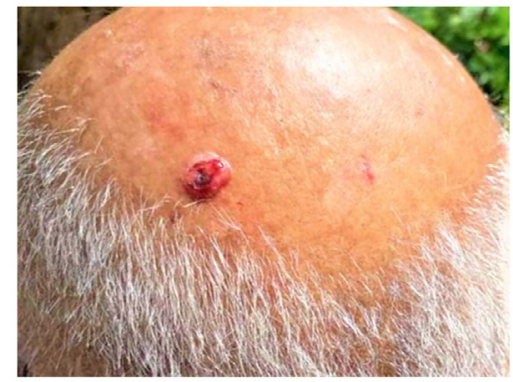

Figure 1. Clinical appearance of the lesion.

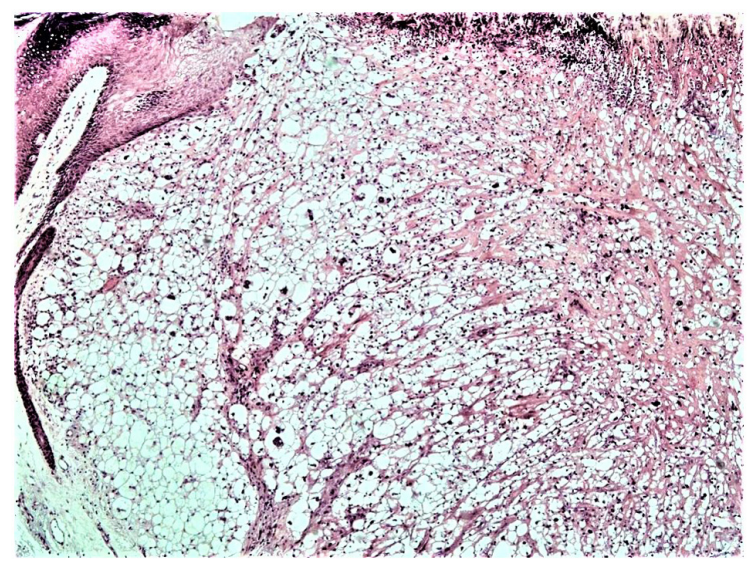

Figure 2. Light microscopy of the tumor: A clear cell dermal proliferation covered by an ulcerated epidermis is shown (hematoxylin and eosin staining; original magnification, x100).

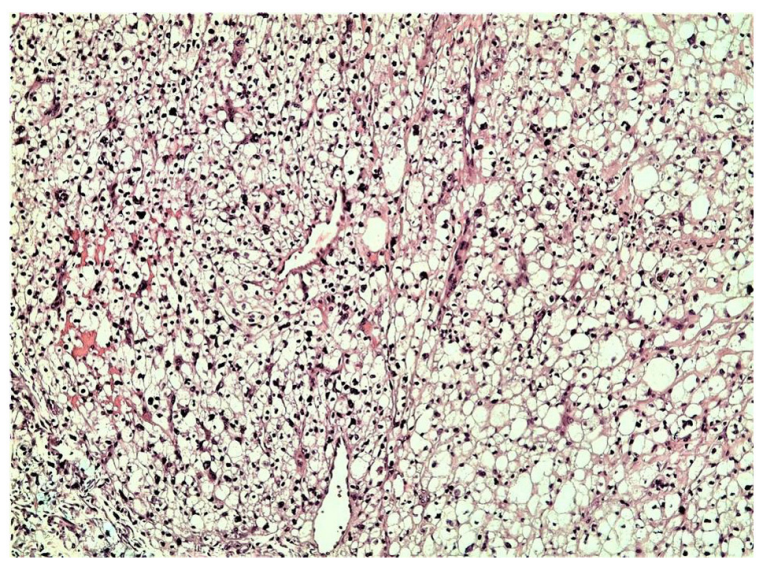

Figure 3. Light microscopy illustrating largely atypical balloon tumor cells arranged in sheets in the superficial and the deep dermis, infiltrating into a hyalinized stroma (hematoxylin and eosin staining; original magnification, x200).

has resolved the difficulty associated with the morphological histopathological diagnosis (17).

Clinically, CCAFX described as tumor or plaque, presents as a flesh-colored or red nodule, varying in size from 0.7 to $2 \mathrm{~cm}$, rarely exceeding $2 \mathrm{~cm}$ (18\% reported in the literature), with a median size of $1.4 \mathrm{~cm}$ (4). It may be ulcerated and tender, but is not painful, as in the case presented herein. The lesion has a rapid growth rate, as also described in the case in the present study; thus, the duration between disease onset 

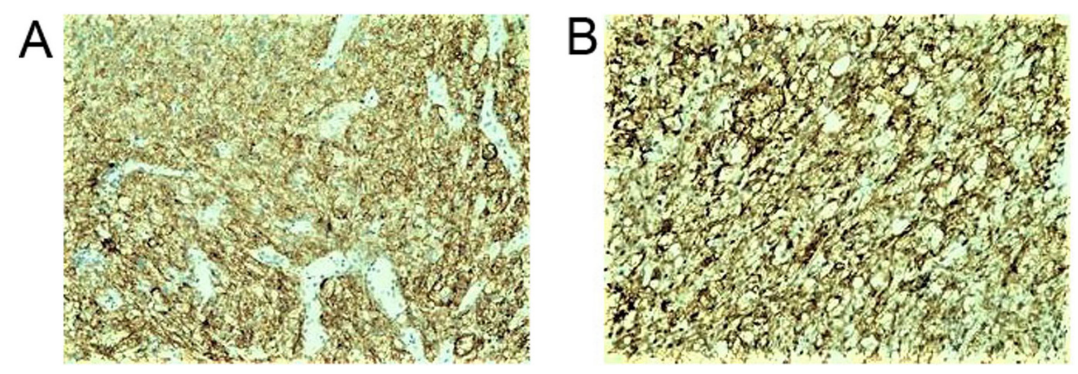

Figure 4. Tumor cells in the dermis strongly expressed (A) CD10 and (B) CD68, as shown by immunohistochemical staining; original magnification, x100.
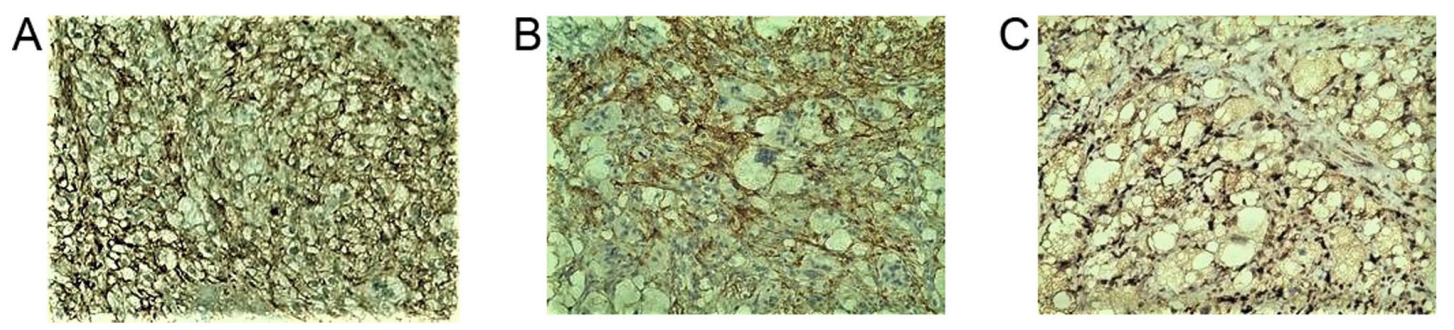

Figure 5. Clear cell atypical fibroxanthoma expresses to (A) CD99, (B) D2-40 and (C) FactorXIIIa varying degrees, as shown by immunohistochemical staining; original magnification, $\mathrm{x} 200$.
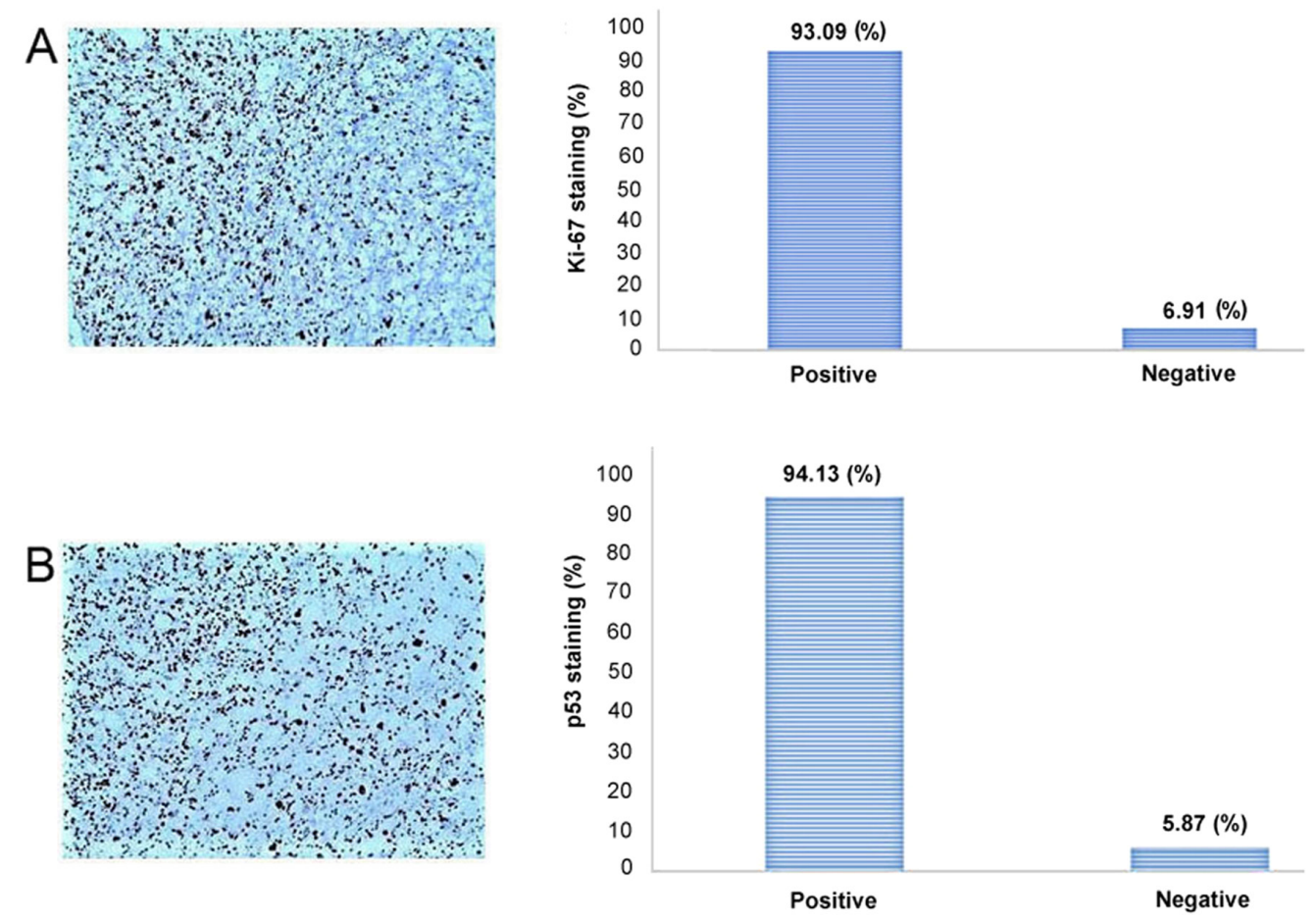

Figure 6. (A) Ki-67 and (B) p53 staining in clear cell atypical fibroxanthoma, as shown by immunohistochemical staining; original magnification x100.

and diagnosis is short, typically within the range of a few months, usually 1-8 months (4). The mean age at diagnosis is 78.7 years, ranging from 70 to 86 years and is more common among males (male/female ratio, 5/1) (4).

Histologically, CCAFX is a well-circumscribed dermal tumor with a symmetric growth pattern, an epidermal collarette, no grenz zone formation, and is composed of epithelioid or spindle-shaped cells arranged haphazardly in sheets (4). The cells have a clear or vacuolated cytoplasm with a subpopulation of balloon cells infiltrating into a hyalinized stroma. The majority of cases are ulcerated lesions without necrosis, vascular or perineural invasion with slight inflammatory infiltrate composed mainly of lymphocytes, mast cells and a few histiocytes (4). The surrounding dermis is loose or fibrous, and the papillary dermis presents a marked accumulation of abnormal elastin known as actinic/solar elastosis (7). Aggressive tumor behavior has been observed, although this is very rare (6), and confers an increased risk of local recurrence 
Table I. Review of the clinicopathological findings of reported CCAFX cases, including the case in the present study.

\begin{tabular}{|c|c|c|c|c|c|c|c|c|c|}
\hline \multicolumn{6}{|c|}{ Clinical data } & \multicolumn{3}{|c|}{ Pathological data } & \multirow[b]{2}{*}{ (Refs.) } \\
\hline Case & Sex & Age, years & Location & Size & Follow-up & Margin & Ulceration & Invasion depth & \\
\hline 1 & M & 87 & $\begin{array}{l}\text { Dorsum of } \\
\text { the hand }\end{array}$ & 10 & AW 3 months & NA & Yes & Deep dermis & (2) \\
\hline 2 & M & 76 & Scalp & 7 & DW 72 months & NA & No & Deep Dermis & (4) \\
\hline 3 & M & 86 & Scalp & 13 & AW 5 months & Pushing & Yes & $\begin{array}{l}\text { Superficial } \\
\text { subcutis }\end{array}$ & (4) \\
\hline 4 & M & 81 & Preauricular & 17 & AW 2 months & Infiltrative & Yes & Deep Dermis & (4) \\
\hline 5 & M & 81 & Scalp & 13 & AW 1 month & Pushing & Yes & Deep Dermis & (4) \\
\hline 6 & $\mathrm{M}$ & 76 & Scalp & 15 & $\begin{array}{l}\text { Recurrence } \\
47 \text { months }\end{array}$ & Pushing & Yes & Deep Dermis & (4) \\
\hline 7 & M & 70 & Scalp & 20 & AW 72 months & Infiltrative & Yes & $\begin{array}{l}\text { Superficial } \\
\text { subcutis }\end{array}$ & (4) \\
\hline 8 & $\mathrm{~F}$ & 86 & Nose & 14 & NA & Pushing & Yes & Dermis & (5) \\
\hline 9 & M & 67 & Ear & 10 & NA & Pushing & Yes & Dermis & (6) \\
\hline 10 & $\mathrm{~F}$ & 63 & Forearm & 14 & NA & Pushing & No & Subcutis & (7) \\
\hline 11 & M & 88 & Scalp & 7 & NA & $\begin{array}{l}\text { NA (shave } \\
\text { biopsy) }\end{array}$ & NA & Dermis & (8) \\
\hline 12 & M & 77 & Forearm & 11 & NA & Pushing & Yes & Dermis & (8) \\
\hline 13 & M & 78 & Temple & 8 & NA & Pushing & Yes & Dermis & (8) \\
\hline 14 & $\mathrm{~F}$ & 90 & Cheek & 25 & AW 18 months & Pushing & Yes & Dermis & (9) \\
\hline 15 & M & 81 & Temple & 40 & AW 24 months & Pushing & Yes & $\begin{array}{l}\text { Superficial } \\
\text { subcutis }\end{array}$ & (10) \\
\hline 16 & $\mathrm{M}$ & 73 & Cheek & 20 & AW 12 months & Pushing & Yes & Deep Dermis & (10) \\
\hline 17 & M & 49 & Ear & 16 & NA & NA & Yes & Dermis & (12) \\
\hline 18 & M & 72 & Lower leg & NA & NA & $\begin{array}{l}\text { NA (shave } \\
\text { biopsy) }\end{array}$ & Yes & NA & (13) \\
\hline 19 & M & 74 & Shoulder & 25 & NA & NA & Yes & Dermis & (14) \\
\hline 20 & M & 86 & Preauricular & 10 & NA & NA & No & Dermis & (33) \\
\hline 21 & M & 78 & Scalp & 13 & AW 12 months & Pushing & Yes & Dermis & $\begin{array}{c}\text { The } \\
\text { present } \\
\text { study }\end{array}$ \\
\hline
\end{tabular}

CCAFX, clear cell atypical fibroxanthoma; DW, died without the disease; AW, alive without the disease; NA, not available.

related to incomplete excision (6). Mohs surgery is considered favorable as it is associated with a lower recurrence rate and tissue sparing compared to a wide local excision which requires a 2 -cm margin and has a higher recurrence rate of $8.7-16 \%$ (18).

Immunohistochemically, CCAFX usually strongly and diffusely expresses CD68 and CD10 (4-12), as in the case presented herein. Other researchers have reported positivity also for Vimentin, procollagen 1 (PC1), SMA, muscle specific actin and lysozyme (11). In addition, the present study demonstrated that CCAFX focally expressed D2-40 and Factor XIIIa, and diffusely CD99 and $\alpha 1$-antichymotrypsin, but did not express cytokeratin or melanocytic markers. Staining for the proliferation index marker, K-i67, ranges from 40 to $50 \%$ in the majority of cases (4), whereas in the present case, the proliferation activity of the critical cells was $93 \%$. The antibodies used and the differential diagnoses are presented in Table II.

The pathologic differential diagnosis of CCAFX includes several primary and metastatic skin tumors consisting of atypical cells with a clear cytoplasm and pleomorphic nuclei. The former include mainly balloon cell melanocytic tumors, clear cell sarcoma (malignant melanoma of soft tissue), clear cell squamous cell carcinoma (clear cell SCC), clear cell basal cell carcinoma (clear cell BCC), metastatic renal cell carcinoma (RCC), metastatic lung and breast carcinoma, metastatic chordoma to the skin, sebaceous carcinoma, trichilemmal carcinoma, clear cell hidradenocarcinoma, pleomorphic liposarcoma and PEComas. Distinguishing features include the collarette formation of the overlying epidermis, tumor cells with indistinct cell boarders, scattered multinucleated giant cells and the location of the tumor in sun 


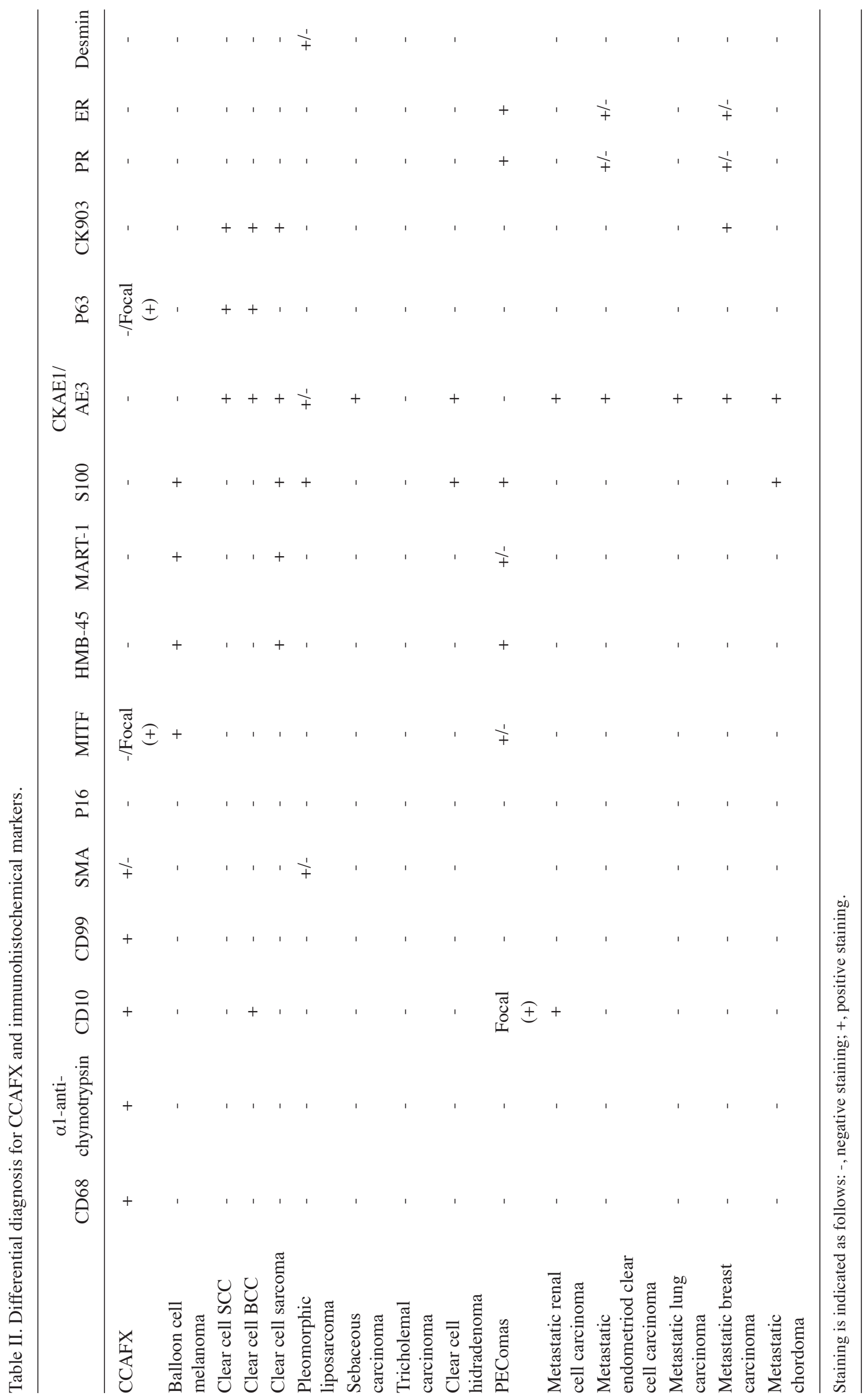


damaged areas of the head and face of elderly individuals (4). As regards the present case, no palisading arrangement at the periphery of the tumor mass, neither clefts between the tumor and stroma were observed, all present to various degrees in basal cell carcinoma $(5,14)$. Immunohistochemically, CCAFX is negative for S100 protein and melanocytic markers, such as HMB45, MART-1, p16 and MITF (7). In a few studies, HMB45 or MITF focal immunoreactivity occasionally has been experienced that exhibits some degree of cross-reactivity with similar epitopes of the tumor $(7,19)$. CCAFX is well-circumscribed with a pushing boarder architecturally, very similar to a nodular balloon-type malignant melanoma (4). However, S100 protein and MART-1, as well as molecular studies for BRAF V600E mutation are not expected in CCAFX (4). p63 which is often found in SCC, is only found in $15-20 \%$ of AFX cases (20). Conversely, clear cell SCC is strongly positive for high molecular weight cytokeratins (CK903), cytokeratin AE1/AE3 and p63 that allow its distinction from CCAFX (20). More importantly, CCAFX should be distinguished from metastatic adenocarcinomas particularly from a renal origin, lung and breast, based on the history, clinical and laboratory findings. Metastatic RCC may pose a significant differential diagnostic problem, particularly if it involves a limited biopsy sample characterized by immunoreactivity for CD10 (4). Abundant amounts of mucins in neoplastic cells positively stained for PAS that lack a delicate vasculature and form a tubulopapillary pattern favor metastatic RCC, features that may distinguish it from CCAFX morphologically (8). Metastatic RCC is the most common metastatic tumor from internal organs, although other tumors include lung, breast and ovarian cancer with clear cell morphology, but negative for CD68 and CD99 and positive for cytokeratins (4). According to the findings presented in this study, CCAFX does not express hormonal receptors [estrogen receptor (ER) or progesterone receptor $(\mathrm{PR})]$ and these findings may be of some assistance in differentiating CCAFX from metastatic breast or endometrioid clear cell carcinomas.

Pleomorphic liposarcoma and other clear cell sarcomas are rarely confined to the superficial dermis without extension to the subcutaneous fat (4). Liposarcoma, as well as chordoma are positive for S100 and chordoma is also positive for cytokeratins (11). CCAFX is well circumscribed and has a pushing boarder no lobular or cribriform architecture and no glandular differentiation (presence of ducts and tubules) or positively stained PAS hyaline material surrounding the lesion, as often present in cutaneous adnexal tumors (11). PEComas and clear cell hidradenocarcinoma are more frequent on the limbs, consisting of palely basophilic cells containing abundant PAS positive glycogen and they are also positive for cytokeratin (4). Tumors that have a diffuse growth pattern connecting to the subcutis and beyond with necrosis and blood vessel invasion should be classified as pleomorphic dermal sarcomas (PDS) according to the WHO 2018 edition (15). A recent study presenting 71 cases, meeting the criteria for both AFX and PDS, indicated that a spindle cell morphology was associated with recurrence, deep infiltration and aggressive behavior (21).

The differentiation/histogenesis of CCAFX is not precisely known and this entity was classified for the first time by WHO in 2018 under the title Tumors of uncertain differentiation (15). The overall pathologic features (dermal tumor with no connection to the subcutis, with nuclear pleomorphism and atypia) and the evaluation of IHC phenotype (expression of histiocytic markers such as CD68, CD163 and a1-antichymotrypsin) favor an origin from fibroblasts and histiocytes (macrophage-like cells) (3). The case presented herein was negative for SMA, often found positive in AFX, as well as for Desmin and Calponin, both stained strongly in leiomyosarcoma (22). In view of the fact that CD10 is generally considered as a sensitive marker (and most of the times the only positive marker) in CCAFX, this finding casts a shadow on the alleged fibroblastic/fibrohistiocytic origin of this tumor (15).

In contrast to other lesions that resemble CCAFX and have a poor prognosis, CCAFX is a dermal tumor that behaves in a low-grade manner, has a more indolent course and only $5 \%$ of cases recur with minimal metastatic potential $(23,24)$. The tumor metastatic potential ranges from $<1$ to $5 \%$ in the literature, although most often, the criteria for the diagnosis are not clear and these cases demonstrate features similar to pleomorphic dermal sarcomas (25). Overall, AFX has no tendency for local recurrence or distant metastases, and chemotherapy has proven ineffective for treatment $(18,24)$. More recent guided molecular therapies, such as molecular inhibitors of the RAS pathway may be promising in unresectable or metastatic tumors (26-29).

The recommended treatment for CCAFX is wide surgical excision with at least $2 \mathrm{~cm}$ tumor-free margins in order to reduce the risk of local recurrence (17). In unresectable cases, radiation therapy may be more suitable. However, there are no guidelines available on the radiation therapy based on the optimal possible dosing, type or frequency for this adjuvant therapy (17). Mohs micrographic surgery was recently applied for AFX tumors due to its commonly accepted advantages for margin evaluation. In a series of 91 patients over a 20 -year period treated with wide surgical excision and Mohs micrographic surgery, no patients exhibited recurrence with Mohs surgery vs. $8.7 \%$ with wide surgical excision (18). Furthermore, the majority of the cases arise on the head and face, and wide excision may be difficult, if not impossible.

A full-body skin examination is warranted in order to detect a clinically occult AFX from another site (23). Distant metastases have rarely been reported, although complete regional lymph node examination should also be carried out in order to identify signs of metastatic disease (23). The patients should be followed-up every six months for a long period of time, since metastases may develop after several years (23). One of the six patients presented in the study by Tardío et al (4) had a local recurrence 47 months after the first excision, whereas the case presented in the study by Javier et al (11) exhibited recurrence within few weeks after the first excision.

AFX has been reported in association with Li-Fraumeni syndrome, including Xeroderma pigmentosum $(30,31)$. Activating mutations have been found in the TP53 gene (32), in the CDKN2A gene (31) and in the promoter region of the TERT gene (27). However, due to the small number of cases, these associations may be fortuitous in CCAFX, although there is a strong association with ultraviolet radiation exposure 
and immunosuppression, which is the major risk factor for this tumor. In the present case report, universal strong nuclear immunohistochemical staining for p53 was noted in the tumor cells. According to the study by Crowson et al the ultraviolet light-induced mutagenesis of p53 may be a clue to the etiopathogenesis of CCAFX and its predilection for sun-exposed areas of the body (8). Based on the present findings the author concluded that male baldness may be an associated adverse effect on the associated ultraviolet light-induced CCAFX and its predilection for the scalp in the male population. This lesion has been also reported in association with other UV-induced skin superficial lesions, such as Bowen disease (33) and actinic keratosis (13). These associations support the common etiopathogenesis of CCAFX with other lesions based on chronic exposure to sun rays.

In conclusion, CCAFX is a rare variant of AFX affecting preferentially the head/face of males in their seventh decade of life. It may be misdiagnosed, since it has several histological differential diagnoses, including several types of primary and metastatic skin tumors. Wide-rage immunohistochemical analyses are crucial for excluding other malignancies. The disease has a relatively favorable prognosis; however, the tumor should be excised with wide margins in order to minimize the risk of recurrence.

\section{Acknowledgements}

Not applicable.

\section{Funding}

No funding was received.

\section{Availability of data and materials}

The datasets used and/or analyzed during the current study are available from the corresponding author on reasonable request.

\section{Author's contributions}

The author, PK, wrote and prepared the manuscript, and obtained the patient data. The author confirms the authenticity of all the raw data and has read and approved the final manuscript.

\section{Ethics approval and consent to participate}

The patient provided his informed consent prior to the preparation of the present study.

\section{Patient consent for publication}

The patient provided his informed consent for his clinical data to be published. The images of the patient and clinical data were provided by the daughter of the patient.

\section{Competing interests}

The author declares that he has no competing interests.

\section{References}

1. Helwig EB: Atypical fibroxandioma: Proceedings of 18th annual tumor seminar of San Antonio society of pathologists. Tex State J Med 59: 664-667, 1961.

2. Patterson JW, Konerding H and Kramer WM: 'Clear cell' atypical fibroxanthoma. J Dertmatol Surg Oncol 13: 1109-1114, 1987.

3. Longacre TA, Smoller BR and Rouse RV: Atypical fibroxanthoma: Multiple immunohistologic profiles. Am J Surg Pathol 17: 1199, 1993.

4. Tardío JC, Pinedo F, Aramburu J, Martínez-González MÁ, Arias D, Khedaoui R, Suárez-Massa D and Santonja C: Clear cell atypical fibroxanthoma: Clinicopathological study of 6 cases and review of the literature with special emphasis on the differential diagnosis. Am J Dermatopathol 38: 586-592, 2016.

5. Kemmerling R, Dietze O, Müller S and Neureiter D: Aspects of the differential diagnosis of clear-cell lesions of the skin in connection with the rare case of a clear-cell atypical fibroxanthoma. Pathol Res Pract 205: 365-370, 2009.

6. Murali R and Palfreeman S: Clear cell atypical fibroxanthomareport of a case with review of the literature. J Cutan Pathol 33: 343-348, 2006

7. Cai JP and Randall B: HMB-45 expression in a clear cell variant of atypical fibroxanthoma. J Cutan Pathol 33: 186-188, 2006.

8. Crowson AN, Carlson-Sweet K, Macinnis C, Taylor JR, Battaglia T, LaMar WL, Minor D, Sutter S and Hill T: Clear cell atypical fibroxanthoma: A clinicopathologic study. J Cutan Pathol 29: 374-381, 2002.

9. Lazaro-Santander R, Andres-Gozalbo C, Rodriguez-Pereira C and Vera-Román JM: Clear cell atypical fibroxanthoma. Histopathology 35: 484-485, 1999.

10. Requena L, Sangueza OP, Yus ES and Furio V: Clear-cell atypical fibroxanthoma: An uncommon histopathologic variant of atypical fibroxanthoma. J Cutan Pathol 24: 176-182, 1997.

11. Javier CN, Colón DC, Sánchez JL and Sánchez JE: Clear-cell atypical fibroxanthoma: A combined immunohistochemistry analysis. Am J Dermatopathol 38: 775-779, 2016.

12. Nguyen CM, Chong K and Cassarino D: Clear cell atypical fibroxanthoma: A case report and review of the literature. J Cutan Pathol 43: 538-542, 2016.

13. Goldstein Z, Sarantopoulos G and Smart C: Clear-cell atypical fibroxanthoma: An unusual case in an unusual place. J Cutan Pathol 44: 951-953, 2017.

14. Bedir R, Agirbas S, Sehitoglu I, Yurdakul C and Elmas O: Clear cell atypical fibroxantoma: A rare variant of atypical fibroxanthoma and review of the literature. J Clin Diagn Res 8: FD09-FD11, 2014.

15. Beer T, Calonje E and Wick M: Atypical fibroxanthoma and variants. In: Elder D, Massi D, Scolyer R, Willemze R (eds). WHO classification of skin tumors. IARC Press, Lyon, 2018, pp368-369.

16. Helwig EB and May D: Atypical fibroxanthoma of the skin with metastasis. Cancer 57: 368-376, 1986.

17. Soleymani T and Hollmig ST: Conception and management of a poorly understood spectrum of dermatologic neoplasms: Atypical fibroxanthoma, pleomorphic dermal sarcoma, and undifferentiated pleomorphic sarcoma. Curr Treat Options Oncol 18: 50, 2017.

18. Ang GC, Roenigk RK, Otley CC, Phillips PK and Weaver AL: More than 2 decades of treating atypical fibroxanthoma at mayo clinic: What have we learned from 91 patients? Dermatol Surg 35: 765-772, 2009.

19. Mohanty SK, Sharma S, Pradhan D, Kandukuri SR, Farahani N, Barry C, Wu JM, Frishberg D and Balzer B: Microphthalmiaassociated transcription factor (MiTF): Promiscuous staining patterns in fibrohistiocytic lesions is a potential pitfall. Pathol Res Pract 214: 821-825, 2018.

20. Kanner WA, Brill LB II, Patterson JW and Wick MR: CD10, p63 and CD99 expression in the differential diagnosis of atypical fibroxanthoma, spindle cell squamous cell carcinoma and desmoplastic melanoma. J Cutan Pathol 37: 744-750, 2010.

21. Cesinaro AM, Gallo G, Tramontozzi S and Migaldi MJ: Atypical fibroxanthoma and pleomorphic dermal sarcoma: A reappraisal. J Cutan Pathol 48: 207-210, 2021.

22. Harding-Jackson N, Sangueza M, Mackinnon A, Suster S and Plaza JA: Spindle cell atypical fibroxanthoma: Myofibroblastic differentiation represents a diagnostic pitfall in this variant of AFX. Am J Dermatopathol 370: 509-514, 2015.

23. Soleymani T, Aasi SZ, Novoa R and Hollmig ST: Atypical fibroxanthoma and pleomorphic dermal sarcoma: Updates on classification and management. Dermatol Clin 37: 253-259, 2019. 
24. Cooper JZ, Newman SR, Scott GA and Brown MD: Metastasizing atypical fibroxanthoma (cutaneous malignant histiocytoma): Report of five cases. Dermatol Surg 31: 221-225, 2005.

25. Miller K, Goodlad JR and Brenn T: Pleomorphic dermal sarcoma. Adverse histologic features predict aggressive behavior and allow distinction from atypical fibroxanthoma. Am J Surg Pathol 36: 1317-1326, 2012.

26. Helbig D, Quaas A, Mauch C, Merkelbach-Bruse S, Büttner R, Emberger M, Wobser M, Rüsseler V, Pütz K, Binot E, et al: Copy number variations in atypical fibroxanthomas and pleomorphic dermal sarcomas. Oncotarget 8: 109457-109467, 2017.

27. Griewank KG, Murali R, Puig-Butille JA, Schilling B, Livingstone E, Potrony M, Carrera C, Schimming T, Möller I, Schwamborn M, et al: TERT promoter mutation status as an independent prognostic factor in cutaneous melanoma. J Natl Cancer Inst 106: dju246, 2014.

28. Griewank KG, Wiesner T, Murali R, Pischler C, Müller H, Koelsche C, Möller I, Franklin C, Cosgarea I, Sucker A, et al: Atypical fibroxanthoma and pleomorphic dermal sarcoma harbor frequent NOTCH1/2 and FAT1 mutations and similar DNA copy number alteration profiles. Mod Pathol 31: 418-428, 2018.
29. Helbig D, Ihle MA, Putz K, Tantcheva-Poor I, Mauch C, Büttner R and Quaas A: Oncogene and therapeutic target analyses in atypical fibroxanthomas and pleomorphic dermal scarcomas. Oncotarget 7: 21763-21774, 2016

30. Dei Tos AP, Maestro R, Doglioni C, Gasparotto D, Boiocchi M, Laurino L and Fletcher CD: Ultraviolet-induced p53 mutations in atypical fibroxanthoma. Am J Pathol 145: 11-17, 1994.

31. Soufir N, Ribojad M, Magnaldo T, Thibaudeau O, Delestaing G, Daya-Grosjean L, Rivet J, Sarasin A and Basset-Seguin NJ: Germline and somatic mutations of the INK4a-ARF gene in a xeroderma pigmentosum group C patient. J Invest Dermatol 119: 1355-1360, 2002.

32. Lee SM, Zhang W and Fernandez MP: Atypical fibroxanthoma arising in a young patient with Li-Fraumeni syndrome. J Cutan Pathol 41: 303-307, 2014.

33. Suárez-Vilela D, Izquierdo-García F, Domínguez-Iglesias F and Méndez-Álvarez JR: Combined papillated bowen disease and clear cell atypical fibroxanthoma. Case Rep Dermatol 2: 69-75; 2010 .

This work is licensed under a Creative Commons Attribution-NonCommercial-NoDerivatives 4.0 International (CC BY-NC-ND 4.0) License. 